\title{
SPL Tissue Form Product Type Terminology
}

National Cancer Institute

\section{Source}

National Cancer Institute. SPL Tissue Form Product Type Terminology. NCI Thesaurus.

Code C133250.

Terminology used to qualify the information pertaining to tissue form product types in the framework of the Structured Product Labeling documents. 